\title{
CONPADRI-I Regimen
}

National Cancer Institute

\section{Source}

National Cancer Institute. CONPADRI-I Regimen. NCI Thesaurus. Code C10001.

A chemotherapy regimen consisting of cyclophosphamide, vincristine, melphalan, and doxorubicin for the treatment of osteosarcoma. 